\title{
Emotional Intelligence of medical students and its association with their Psychological health
}

\author{
Mahaur, R. $^{1}$, Jain, $P^{2}{ }^{2}$, Jain, $A . K^{3}$
}

\begin{abstract}
Introduction: Emotional intelligence (EI) involves perception, expression and management of intrapersonal and interpersonal emotions. The potential role of $E \mathrm{I}$ in emotional health and professional success amongst various healthcare personnel has been reported recently. This study was conducted to evaluate psychological health and El of newly admitted medical undergraduate students, explore association between the two and to determine their socio-demographic correlates.
\end{abstract}

Methods: It was a cross-sectional, self-reported, questionnaire-based study conducted on 224 undergraduate medical students who had completed their first week in the medical college. Psychological health was assessed by Depression Anxiety Stress Scale-21 (DASS-21) and EI was measured by Trait Emotional Intelligence Questionnaire-short form (TEIQue-sf).

Results: The prevalence of symptoms of depression, anxiety and stress amongst participants was $49.55 \%, 71.43 \%$ and $33.93 \%$ respectively. Significant negative correlation $(p<0.001)$ of DASS-21 with global trait El and its subscale scores was found. Females, metropolitan residents and participants who self-chose medical career scored significantly higher on global El as compared to their counterparts. Females scored higher in wellbeing and emotionality subscale as compared to males. High sociability score was seen in day-scholars, metropolitan residents and students who self-chose medical career.

Conclusions: Results indicate a high prevalence of psychological morbidity amongst newly admitted medical undergraduate students. Moreover, the strong negative association seen between El and psychological health indicates that high El contributes towards better self-perception of psychological wellbeing. Furthermore, El is also influenced by both personal and environmental factors.

Key-words: Emotional Intelligence, medical students, mental wellbeing, psychological health.

\section{Introduction}

Psychological health refers to a state of mental wellbeing in which an individual realizes one's own cognitive and emotional capabilities, maintain healthy relationships, function effectively with a sense of purpose in life (Huppert, 2009).

\footnotetext{
${ }^{1}$ Senior resident, Department of Physiology, Maulana Azad Medical College, New Delhi

${ }^{2}$ Associate Professor, Department of Physiology, Maulana Azad Medical College, New Delhi

${ }^{3}$ Director Professor, Department of Physiology, Maulana Azad Medical College, New Delhi

Corresponding Author:

Dr. Rashmi Mahaur,

Department of Physiology, 2nd floor Pathology Block, Maulana Azad, Bahadur Shah Zafar Marg, New Delhi

E mail:drrashmi1501@gmail.com
}

DOI: http://doi.org/10.4038/seajme.v12i2.49
Over the past decades, a global increase in the prevalence of psychological morbidity amongst various medical and healthcare professionals has been observed (Chou et al., 2014). Significant numbers of studies have reported mild to severe cases of depression, anxiety, stress (Abdallah \& Hala, 2014; Iqbal et al., 2015), addiction to alcohol or drugs (Melaku et al., 2015), burnout as well as suicidal tendencies in doctors (Dahlin \& Runeson, 2007) and medical students in comparison to the general population and their peer groups (Dahlin et al., 2005).

Moreover, development of symptoms of mental distress has been reported to occur early even in the psychologically healthy students during their formative years in medical institutes (Yusoff et al., 2013). This, in

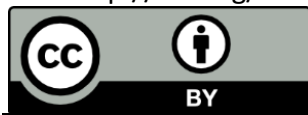

(C) SEAJME. This is an Open Access article distributed under the terms of the Creative Commons Attribution License (http://creativecommons.org/licenses/by/4.0/), which permits unrestricted use, distribution, and reproduction in any medium, provided the original author and source are credited 
turn, predisposes to decreased attention and learning ability in them during the student life and is potentially detrimental during their clinical practice in future (Cozens \& Greenhalgh, 1997).

Recently, emotional intelligence (EI) is increasingly being discussed as having a potential role in medicine and other healthcare disciplines, both for personal psychological health and professional practice (Arora et al., 2010). El refers to an ability to monitor intrapersonal and interpersonal feelings and emotions, to discriminate among them and to use this information to guide one's thinking and actions while adapting and coping successfully to deal with adverse situations and environmental demands (Brannick et al., 2009).

Early conceptualization of El referred to it as ability, reflecting primarily the efficacy of cognitive ability related to emotions and its information processing (Salovey \& Mayer, 1990). Ability El was assessed mainly by maximum performance-based test (Mayer et al., 2008).

Subsequently, trait El gained attention as a relevant EI measure because it measures the self-perception of emotions based on inherent personality of the individual using self-report questionnaire (Petrides et al., 2010). Beneficial role of $\mathrm{El}$ on aspects of emotional health, relationships (Masood \& Mazahir, 2015), selfmotivation, work success (Nikolaou \& Tsaousis, 2002), leadership (Cooper \& Sawaf, 1997) and satisfaction in life (Palmer et al., 2002) are being reported suggesting that, without these skills or abilities, individuals will not be as successful.

However, this is not a universal finding and there have often been inconsistent results of $\mathrm{El}$ on the variance in health. Researchers have found that individuals with higher El may have maladaptive consequences and even reacted more strongly to adverse circumstances leading to greater psychological distress in them (Petrides \& Furnham, 2003). Although, the research in this area is still in its incipient stage, these emerging links between EI and psychological health point towards the potential role of $\mathrm{El}$ as a predictor of various life outcomes.

Recently few studies have shown that higher $\mathrm{EI}$ is associated with better doctor-patient communication, effective coping with work pressure and improved team work amongst doctors (Arora et al., 2010). Much less is known about the El of medical students in their initial formative year and its relationship with their psychological wellbeing. Merging studies on $\mathrm{El}$ and psychological health may provide valuable insights into the emotional traits of an individual and its implications on their mental wellbeing.

The present study was conducted on the newly admitted medical undergraduate students with the aim to

(i) Assess the psychological health (using DASS-21) and emotional intelligence (using TEIQue-sf)

(ii) Evaluate the inter-relationship between EI and psychological health as well as to determine their socio-demographic correlates.

\section{Methods}

The study was designed as a cross-sectional, self-administered questionnaire-based trial conducted on newly admitted medical students in the medical college. The approval of the Institutional Ethical Committee was obtained prior to conduction of the study.

\section{Participants}

Out of a total of 250 new medical undergraduate students, 232 students volunteered to participate in the study. The purpose of the study was fully explained to the participants and their informed signed consent was taken. Eight students who returned incomplete forms were excluded from the study. The total number of participants who were finally included in the study was 224 . The identity of each student was kept anonymous by allocating a random number to each one of them and strict confidentiality was maintained.

\section{Data Collection}

Data was collected using self-reported, predesigned and pre-tested questionnaires (in English language) at the completion of their first week in the medical college. Sociodemographic data was collected by using a structured form in which information regarding their gender, age, residence of student after admission to college; family location and income were obtained.

The participants were then asked to complete the paper-based version of self-report 
questionnaires on psychological health and emotional intelligence. In completing these questionnaires, the individual was required to indicate on the given likert scale how, each statement applied to them over the previous week.

\section{Measures}

(i) Depression, Anxiety and Stress Scale (DASS-21):

DASS-21 measures prevalence and severity of symptoms of depression, anxiety and stress. It has 21 questions with seven items for each subscale. The items are responded on a 4-point likert scale ranging from 0 (did not apply to me at all over the last week) to 3 (applied to me very much or most of the time over the past week). Scores for identified items of each subscale are summed. Because the DASS-21 is a short version of the DASS (the Long Form has 42 items), the final score of each item groups (Depression, Anxiety and Stress) is multiplied by two. The severity of the symptoms of Depression, Anxiety and Stress can be graded into normal, mild, moderate, severe and extremely severe based on the scores (Lovibond \& Lovibond, 1995) (Table 1).

Table 1: DASS-21 subscales severity ratings

\begin{tabular}{lccc}
\hline \multicolumn{1}{c}{ Severity } & Depression & Anxiety & Stress \\
\hline Normal & $0-9$ & $0-7$ & $0-14$ \\
Mild & $10-13$ & $8-9$ & $15-18$ \\
Moderate & $14-20$ & $10-14$ & $19-25$ \\
Severe & $21-27$ & $15-19$ & $26-33$ \\
Extremely Severe & $28+$ & $20+$ & $34+$ \\
\hline
\end{tabular}

Note: DASS-21 scale is from Lovibond \& Lovibond (1995).

(ii) Trait Emotional Intelligence Questionnaireshort form (TEIQue-sf):

Trait El measures El by identifying emotions experienced by an individual related to his or her personality (Petrides et al., 2010). TEIQuesf is a short version of trait El scale used for rapid assessment of global trait El. It also evaluates four factors namely well-being, emotionality, sociability and self-control. It is a sensitive instrument with good predictive validity, psychometric properties and adaptability across different countries (Cooper \& Petrides, 2010). It has 30 questions including well-being ( 6 items), self-control (6 items), sociability (6 items), emotionality (8 items) and remaining 4 items contribute to global trait $\mathrm{El}$ score only. Each item is responded on a Likert scale ranging from 1 (completely disagree) to 7 (completely agree). It yields global trait El score by summing up all the item scores. The score ranges from 30 to 210. The four factors (subscales) of trait El are evaluated by summing up item scores for each factor. The possible ranges of scores for each factor are wellbeing (6-42), self-control (6-42), emotionality (8-56) and sociability (6-42).

\section{Statistical Analysis}

The data was analysed using SPSS version 20.0 for Windows (SPSS, Inc., Chicago,
Illinois, USA). All data collection forms were given serial numbers. A reliability analysis of all scales was done by calculating Cronbach's alpha internal consistency coefficients using the data from all participants. Any missing items not completed by the participants were replaced by median for that item.

Descriptive statistics in the form of mean, standard deviation (SD) was calculated for the DASS-21 and TEIQue-sf scores. A demographic characteristic, prevalence of depression, anxiety and stress in students was expressed in frequency and percentage.

ANOVA was used to analyse any difference in DASS-21 scores and TEIQue-sf scores among students according to their socio-demographic characteristics. A correlation between psychological health and El was calculated using Pearson's correlation test. A $p$ value of $<0.05$ was considered significant for all analyses.

\section{Results}

Demographic characteristics of the
participants

The mean age of participants was $18.20 \pm 1.10$ years. 138 participants were male $(61.6 \%)$ and 86 were females $(38.4 \%)$. Out of total 
participants 97 (43.3\%) were hostellers and approximately $12 \%$ belonged to either village or town. The family income of almost half
(47.3\%) of the participants was $>1$ lakh rupees per month. Almost $90 \%$ had self-chosen this career (Table 2).

Table 2: Table showing relation of socio-demographic characteristic of first year medical students with their psychological health (DASS-21)

\begin{tabular}{|c|c|c|c|c|c|}
\hline & Variables & Frequency (\%) & Depression & Anxiety & Stress \\
\hline \multirow{2}{*}{ Gender } & Males & $138(61.6 \%)$ & $10.75 \pm 7.845$ & $11.23 \pm 6.413$ & $13.54 \pm 7.173$ \\
\hline & Females & $86(38.4 \%)$ & $9.02 \pm 7.048$ & $10.84 \pm 7.574$ & $12.67 \pm 7.270$ \\
\hline \multirow{2}{*}{$\begin{array}{l}\text { Residence } \\
\text { of students }\end{array}$} & Hostellers & $97(43.3 \%)$ & $11.09 \pm 7.360$ & $11.90 \pm 6.522$ & $14.27 \pm 7.022$ \\
\hline & Day-scholars & $127(56.7 \%)$ & $9.32 \pm 7.685$ & $10.46 \pm 7.083$ & $12.39 \pm 7.229$ \\
\hline \multirow{3}{*}{$\begin{array}{l}\text { Location of } \\
\text { Family }\end{array}$} & Metro city & $119(53.1 \%)$ & $9.06 \pm 7.798$ & $10.71 \pm 7.067$ & $12.47 \pm 7.612$ \\
\hline & Non-metro city & $78(34.8 \%)$ & $11.23 \pm 7.267$ & $10.92 \pm 5.870$ & $14.26 \pm 6.741$ \\
\hline & Town/village & $27(12.1 \%)$ & $11.33 \pm 7.082$ & $13.19 \pm 8.399$ & $13.41 \pm 6.271$ \\
\hline \multirow{4}{*}{$\begin{array}{l}\text { Family } \\
\text { Income }\end{array}$} & $<20,000$ per month & $22(9.8 \%)$ & $9.27 \pm 6.065$ & $11.36 \pm 6.514$ & $13.27 \pm 5.539$ \\
\hline & $20,000-50,000$ per month & $49(21.9 \%)$ & $10.41 \pm 7.035$ & $11.92 \pm 5.582$ & $12.94 \pm 6.521$ \\
\hline & $50,000-1,00,000$ per month & $47(21 \%)$ & $11.66 \pm 9.309$ & $13.23 \pm 8.220$ & $14.51 \pm 7.940$ \\
\hline & $>1,00,000$ per month & $106(47.3 \%)$ & $9.42 \pm 7.235$ & $9.68 \pm 6.591$ & $12.74 \pm 7.444$ \\
\hline \multirow{2}{*}{$\begin{array}{l}\text { Choice of } \\
\text { career }\end{array}$} & Self & $198(88.4 \%)$ & $9.74 \pm 7.355$ & $10.80 \pm 6.677$ & $12.86 \pm 6.882$ \\
\hline & Parents & $26(11.6 \%)$ & $12.77 \pm 8.820$ & $13.23 \pm 8.002$ & $\begin{array}{r}15.85 \pm 8.889 \\
(p=0.046)\end{array}$ \\
\hline
\end{tabular}

Measures

The mean (SD) values and internal reliability (Cronbach's alpha) of questionnaire on psychological health (DASS-21) and emotional intelligence (TEIQue-sf) are presented in Table 3. Both the questionnaires used in the study showed an acceptable reliability with Cronbach's alpha value $>0.7$ (Tavakol \& Dennick, 2011).

Table 3: The mean \pm SD scores and reliability (Cronbach's alpha value) of psychological health scale (Depression, anxiety and stress subscales of DASS-21) and trait EI (TEIQue-sf) in first year medical students

\begin{tabular}{lcc}
\hline \multicolumn{1}{c}{ Variables } & Mean \pm SD & Cronbach's alpha \\
\hline TEIQue-sf global score & $116.2 \pm 19.5$ & 0.86 \\
Wellbeing total score & $30.3 \pm 6.1$ & 0.65 \\
Self-control score & $25.4 \pm 6.1$ & 0.56 \\
Emotionality score & $35.7 \pm 7.4$ & 0.59 \\
Sociability score & $24.8 \pm 6.2$ & 0.63 \\
Depression score & $10.1 \pm 7.6$ & 0.80 \\
Anxiety score & $11.1 \pm 6.9$ & 0.62 \\
Stress score & $13.2 \pm 7.2$ & 0.71 \\
\hline
\end{tabular}


(i) Depression, Anxiety and Stress Scale (DASS-21)

The overall prevalence of symptoms of depression, anxiety and stress amongst the participants were $49.55 \%, 71.43 \%$ and $33.93 \%$ respectively. Severity of symptoms of anxiety was found to be the highest amongst the medical students with approximately one fourth $(25.44 \%)$ of the participants perceiving severe or very severe anxiety. In the depression and stress subscales, symptoms of mild to moderate severity were predominantly reported by $40.54 \%$ and $26.79 \%$ participants respectively (Figure 1a-c). Univariate analysis showed that higher scores on stress subscale were associated with parental choice for opting medical career (Table 2).

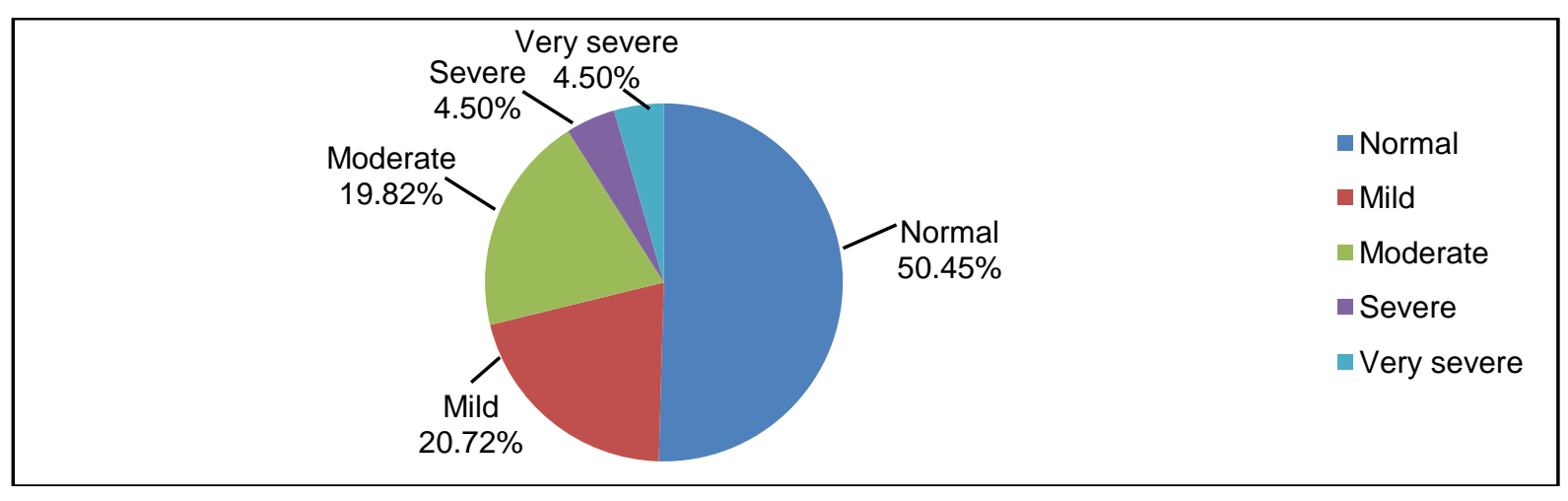

Figure 1(a): Severity of Depression in first year medical students

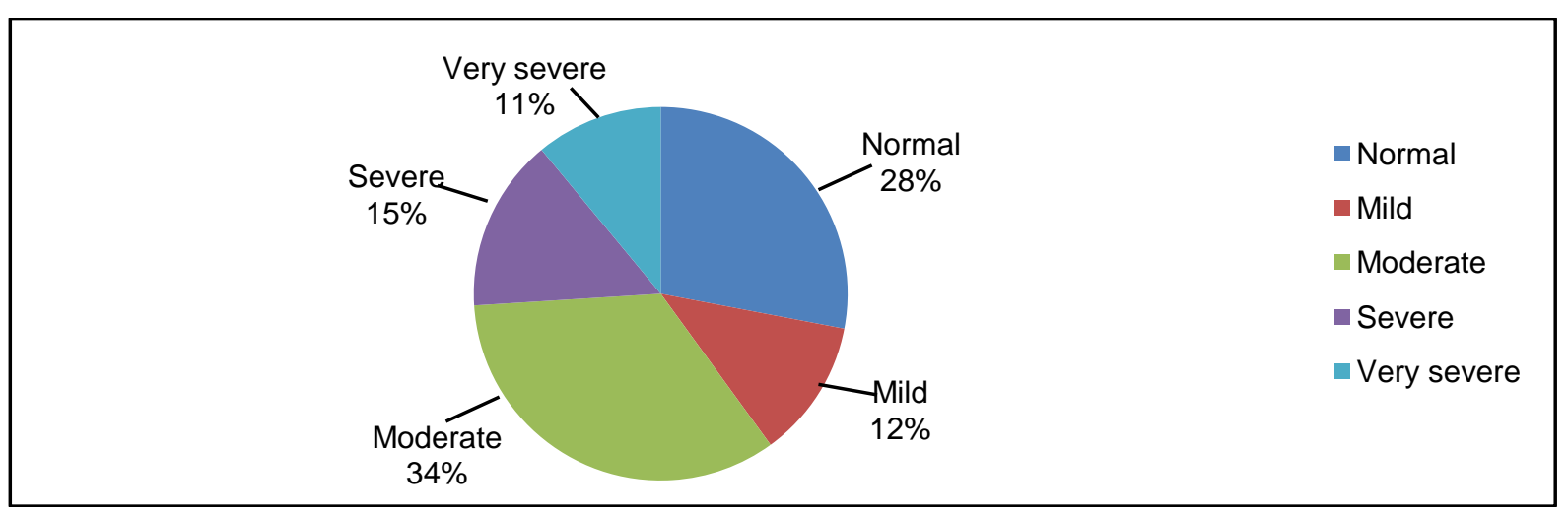

Figure 1(b): Severity of Anxiety in first year medical students

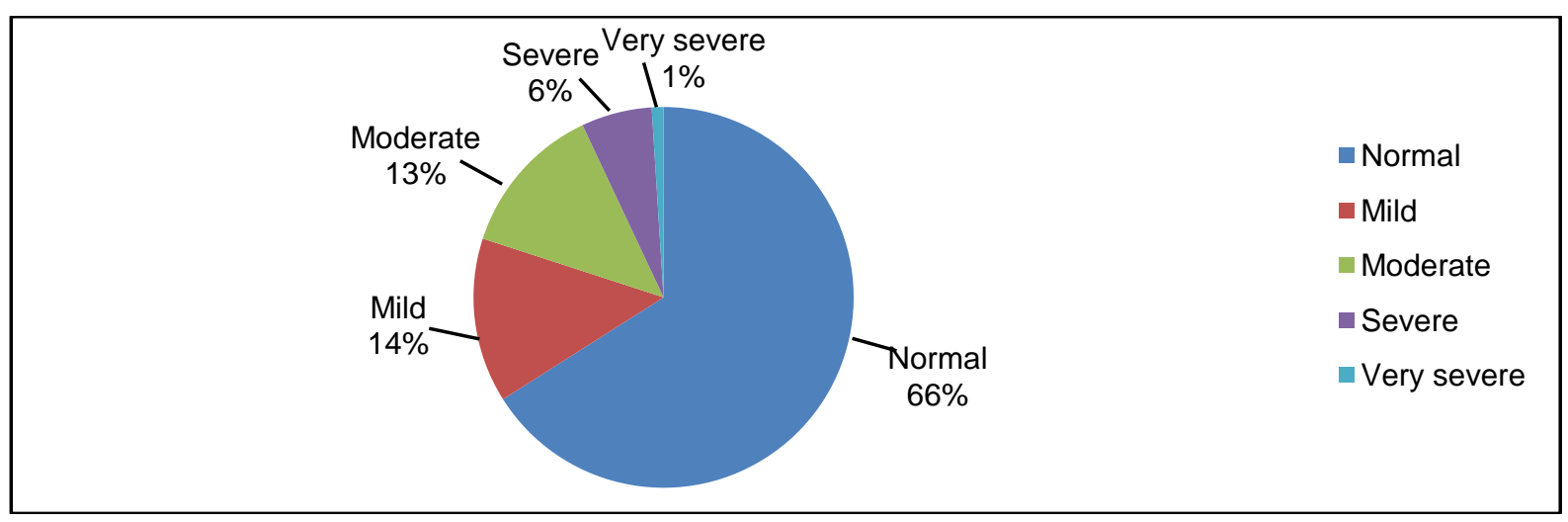

Figure 1(c): Severity of Stress in first year medical students 
(ii) Trait Emotional Intelligence Questionnaireshort form (TEIQue-sf)

Univariate analysis (Table 4) showed that higher scores of global trait El was associated with female gender, metro city residents and those who had self-chosen medical career. Female participants had significantly higher scores in wellbeing $(p=0.021)$ and emotionality
( $p=0.015)$ subscales as compared to male students. Statistically significant difference was also observed in the sociability subscale based on the residence of student $(p=0.025)$, location of their family $(p=0.002)$ and choice of career $(p=0.019)$, with day-scholars, metro city residents and students who self-chose medical career showing higher El scores.

Table 4: Table showing relation of socio-demographic characteristic of first year medical students with their psychological health (DASS-210)

\begin{tabular}{|c|c|c|c|c|c|c|c|}
\hline & Variables & $\begin{array}{c}\text { Frequency } \\
(\%)\end{array}$ & $\begin{array}{l}\text { TEIQue-sf } \\
\text { global score }\end{array}$ & Well being & Self-control & Emotionality & Sociability \\
\hline \multirow[b]{2}{*}{ Gender } & Males & $138(61.6)$ & $114.01 \pm 18.501$ & $29.50 \pm 6.283$ & $25.36 \pm 5.893$ & $34.75 \pm 6.871$ & $24.40 \pm 6.198$ \\
\hline & Females & $86(38.4)$ & $\begin{array}{c}119.60 \pm 20.599 \\
(p=0.036)^{*}\end{array}$ & $\begin{array}{c}31.44 \pm 5.749 \\
(p=0.021)^{*}\end{array}$ & $25.42 \pm 6.331$ & $\begin{array}{l}37.24 \pm 8.08 \\
(p=0.015)^{*}\end{array}$ & $25.50 \pm 6.110$ \\
\hline \multirow{2}{*}{$\begin{array}{l}\text { Residenc } \\
\text { e of } \\
\text { students }\end{array}$} & Hostellers & $97(43.3)$ & $13.35 \pm 18.943$ & $29.92 \pm 5.488$ & $24.64 \pm 5.971$ & $35.03 \pm 7.857$ & $23.76 \pm 6.118$ \\
\hline & Day-scholars & $127(56.7)$ & $118.30 \pm 19.685$ & $30.50 \pm 6.612$ & $25.94 \pm 6.074$ & $36.23 \pm 7.100$ & $\begin{array}{c}25.63 \pm 6.118 \\
(p=0.025) \text { * }\end{array}$ \\
\hline \multirow{3}{*}{$\begin{array}{l}\text { Location } \\
\text { of Family }\end{array}$} & Metro city & $119(53.1)$ & $119.75 \pm 19.786$ & $30.86 \pm 6.427$ & $26.21 \pm 6.170$ & $36.54 \pm 7.217$ & $26.14 \pm 6.305$ \\
\hline & Non-metro city & $78(34.8)$ & $112.96 \pm 19.278$ & $29.65 \pm 5.727$ & $24.60 \pm 6.087$ & $35.05 \pm 7.949$ & $23.65 \pm 5.897$ \\
\hline & Town/village & $27(12.1)$ & $\begin{array}{c}109.56 \pm 15.567 \\
(p=0.009)^{\star *}\end{array}$ & $29.26 \pm 5.946$ & $23.96 \pm 4.950$ & $33.96 \pm 6.648$ & $\begin{array}{l}22.37 \pm 5.024 \\
(\mathrm{p}=0.002)\end{array}$ \\
\hline \multirow{4}{*}{$\begin{array}{l}\text { Family } \\
\text { Income }\end{array}$} & $\begin{array}{l}<20,000 \text { per } \\
\text { month }\end{array}$ & $22(9.8)$ & $113.14 \pm 16.042$ & $28.50 \pm 5.771$ & $25.27 \pm 5.824$ & $34.27 \pm 6.699$ & $25.09 \pm 4.374$ \\
\hline & $\begin{array}{l}20,000-50,000 \\
\text { per month }\end{array}$ & $49(21.9)$ & $114.63 \pm 17.710$ & $29.24 \pm 6.441$ & $25.78 \pm 5.273$ & $35.96 \pm 7.106$ & $23.65 \pm 5.547$ \\
\hline & $\begin{array}{l}50,000-1,00,000 \\
\text { per month }\end{array}$ & $47(21)$ & $114.21 \pm 21.454$ & $29.66 \pm 6.312$ & $25.38 \pm 6.131$ & $35.13 \pm 8.451$ & $24.04 \pm 6.400$ \\
\hline & $\begin{array}{l}>1,00,000 \text { per } \\
\text { month }\end{array}$ & $106(47.3)$ & $118.35 \pm 19.997$ & 31.335 .886 & $25.22 \pm 6.457$ & $36.15 \pm 7.317$ & $25.65 \pm 6.596$ \\
\hline \multirow{2}{*}{$\begin{array}{l}\text { Choice of } \\
\text { career }\end{array}$} & Self & $198(88.4)$ & $117.37 \pm 19.55$ & $30.75 \pm 5.955$ & $25.56 \pm 6.058$ & $35.89 \pm 7.447$ & $25.17 \pm 6.201$ \\
\hline & Parents & $26(11.6)$ & $\begin{array}{c}106.88 \pm 16.408 \\
(p=0.01)^{\star *}\end{array}$ & $\begin{array}{l}26.38 \pm 6.306 \\
(p=0.001)^{\star * *}\end{array}$ & $24.00 \pm 5.926$ & $34.35 \pm 7.424$ & $\begin{array}{c}22.15 \pm 5.349 \\
(p=0.019) \text { * }\end{array}$ \\
\hline
\end{tabular}

Note: Trait emotional intelligence questionnaire-short form (TEIQue-sf) is from Cooper \& Petrides (2010). ${ }^{*} p \leq 0.05$-significant, ${ }^{* *} p \leq 0.01$-very significant, ${ }^{* * *} p \leq 0.001$-highly significant.

\section{Correlations}

As shown in Table 5, there was a significant negative correlation between global TEIQue-sf and DASS-21 scores with $r$ values between-
0.41 to- $0.54, p<001$. Depression, anxiety and stress subscales of DASS-21 were also found to be correlated significantly with all factors of TEIQue-sf $(r=0.23$ to- $0.56 ; p<0.001)$.

Table 5: Correlation of psychological health (GHQ-12 and DASS-21) with emotional intelligence (TEIQue-sf) of first year medical students.

\begin{tabular}{|c|c|c|c|c|c|}
\hline Variables & TEIQue-sf & Wellbeing & Self-control & Emotionality & Sociability \\
\hline Depression & $\begin{array}{c}r=-0.54 \\
p<0.001^{\star \star \star}\end{array}$ & $\begin{array}{c}r=-0.56 \\
p<0.001^{\star \star \star}\end{array}$ & $\begin{array}{c}r=-0.44 \\
p<0.001^{\star * *}\end{array}$ & $\begin{array}{c}r=-0.28 \\
p<0.001^{\star * *}\end{array}$ & $\begin{array}{c}r=-0.38 \\
p<0.001^{\star * \star}\end{array}$ \\
\hline Anxiety & $\begin{array}{c}r=-0.41 \\
p<0.001^{* * *}\end{array}$ & $\begin{array}{c}r=-0.33 \\
p<0.001^{* * *}\end{array}$ & $\begin{array}{c}r=-0.42 \\
p<0.001^{* * *}\end{array}$ & $\begin{array}{c}r=-0.23 \\
p<0.001^{* * *}\end{array}$ & $\begin{array}{c}r=-0.28 \\
p<0.001^{\star \star \star}\end{array}$ \\
\hline Stress & $\begin{array}{c}r=-0.49 \\
p<0.001^{\star \star \star}\end{array}$ & $\begin{array}{c}r=-0.49 \\
p<0.001^{\star \star \star}\end{array}$ & $\begin{array}{c}r=-0.47 \\
p<0.001^{* * *}\end{array}$ & $\begin{array}{c}r=-0.29 \\
p<0.001^{* \star *}\end{array}$ & $\begin{array}{c}r=-0.32 \\
p<0.001^{\star \star \star}\end{array}$ \\
\hline
\end{tabular}




\section{Discussion}

The present study is different from earlier studies which assessed either psychological health (Abdallah \& Hala, 2014; lqbal et al., 2015) or emotional intelligence (Brannick et al., 2009) in the medical students. In our study, we assessed both, the psychological health and $\mathrm{El}$ of new entrants to medical undergraduate course who had just completed their first week in the college. It has been postulated that generally the psychological health of students at the start of medical studies is similar or almost similar to their nonmedical peers and tends to worsen during the course of medical training (Jafari et al., 2012). Thus, we reasoned that, assessment of the students by self-reported questionnaires at the very beginning of their professional studies would enable us to discern the inherent psychological and emotional characteristics of these students.

Our DASS-21 data illustrated a high prevalence of psychological morbidity amongst fresh medical undergraduate students of the institute. The scores for psychological distress symptoms (i.e. depression, anxiety and stress) were above the threshold values in more than one-third of the participants. Furthermore, maximum percentage of participants $(71.43 \%)$ reported having symptoms of anxiety. The severity of symptoms of anxiety was also highest with more than one-fourth of the participants who perceived severe or very severe anxiety.

These findings are consistent with studies that have shown higher prevalence of symptoms of anxiety as compared to depression and stress symptoms in participating students (Abdallah \& Hala, 2014; lqbal et al., 2015). Increased anxiety in students may be attributed to their apprehension to settle in unknown new environment of college and hostel, fear of ragging and making new acquaintances.

However, it is noteworthy that the overall prevalence of symptoms of depression and stress observed in our study is much lower as compared with previously published data using DASS subscales (Abdallah \& Hala, 2014; lqbal et al., 2015).

One plausible reason for the relatively low prevalence of psychological distress symptoms in our study as compared to others could be that our participants had just entered the course one week prior and may have still been experiencing the stages of novelty and euphoria. In addition, during this time period, they had yet to face difficult subjects because most of the subjects studied during the initial months are the ones that they have learned during their schooling.

Result of univariate analysis showed that the students who had chosen medical career on their parents' behest had significantly higher scores on stress subscale of DASS-21, thereby, suggesting poor psychological health in them. Lack of enthusiasm and motivation amongst students who had not self-chosen the career could have contributed to significantly higher stress levels in them as compared to students who had come by their own choice. These results of ours are in conformity with previous research works that have shown that the students who joined medical field due to parental pressure were more stressed and afraid to face failure as compared to the ones who join the course by their own will (Acharya, 2003). No significant difference was seen in psychological health based on gender, family location and income.

These observations in our study corroborate with earlier works done in various other Asian countries including India (lqbal et al., 2015; Jafari et al., 2012), that reported no difference in mental wellbeing of participants based on gender or any other socio-demographic characteristics. However, few studies have reported higher prevalence of self-reported psychological morbidity in females as compared to their male counterparts (Abdallah \& Hala, 2014; Grant et al., 2002). This difference could be real or it could be due to the fact that females are more likely to report or express concerns about the presence of symptoms of stress in them (Bayaram \& Bilgel, 2008).

The TEIQue-sf results of the present study reveal that females, metropolitan city students and students who self-chose medical profession, had higher global trait El scores, thereby, suggesting that they had higher El compared to their respective counterparts. Moreover, the relatively greater scores achieved by the female participants on emotionality and wellbeing factors indicates that they were more in touch with their own and people's feelings and were happier, optimistic and more fulfilled in life as compared to the male participants.

Emerging bodies of studies that have been conducted in the last decade have also reported higher El in female college students 
(Austin et al., 2005; Harrod \& Scheer, 2005). However, contradictory findings have also been reported. Few studies have shown that males have better emotional intelligence as compared to females (Yelkikalan et al., 2012) whereas; still others have failed to find any gender difference in El (Sanchez-Ruiz et al., 2010). Considering the fact that in the current sample, number of male participants far exceeded those of female participants, it raises the possibility that part of the findings was influenced by this characteristic. Furthermore, significantly lower sociability scores were observed in hostellers in comparison to day-scholars, in students belonging to town/villages compared to those from metro \& non-metro cities as well as in students who opted medical profession due to their parent's choice.

The sociability factor of trait El scale is a combination of emotion management, assertiveness and social awareness traits and the lower sociability scores in these students suggest that they were less confident in dealing with diverse sorts of people, were shy and reserved and felt less comfortable in social contexts as compared to other participants (Petrides \& Furnham, 2001). Earlier researches have also has shown that El in students, particularly wellbeing and sociability factors are significantly associated with social and cultural environment of the place they are born and brought up in (Yelkikalan et al., 2012). Our study lends also supports this notion that, El is not only influenced by the personal characteristics of a person such as gender but is affected by the environmental factors as well.

In the present study, we found a significant negative association between emotional intelligence and psychological health, thereby indicating that the participants who had higher global trait El scores were emotionally healthier and coped better in the face of adversity as compared to those who had lower global trait El scores. It is noteworthy that this strong negative association was observed between all the four factors of TEIQue-sf with the three subscales of DASS-21.

This echoes previous relevant findings from studies showing that high trait El scores are associated with less burnout and higher job and patient satisfaction (Weng et al., 2011) and lends support to the view that, "El is good for you". However, our results are in contradiction to previous reports where individuals with higher $\mathrm{El}$ reacted more strongly under adverse circumstances leading to greater psychological distress and maladaptive consequences in them (Petrides \& Furnham, 2003; Arora et al., 2011).

Our finding that students with higher EI reported less symptoms of psychological illness than those with low El, suggests that El helps to cope with stressful situations and contributes to better psychological health. Thus, it appears, high El may be a factor abating symptoms of stress in medical students. It can be due to fact that higher emotional intelligence results in better understanding and management of emotions in self and others which helps to adapt and cope with adverse situations. Few studies have also shown that mental health workshops are helpful to develop $\mathrm{El}$ in medical students (Abe et al., 2013; Nelis et al., 2009).

So, enhancing emotional intelligence by training and workshops can enable the students in managing stress as well as promoting mental wellbeing amongst them. Although recently $\mathrm{EI}$ has been studied as a tool for success in job and leadership qualities, but application of El in betterment of mental wellbeing has been less explored. Therefore, more focused studies are required to substantiate beneficial role of $\mathrm{EI}$ in psychological wellbeing of medical students and to further support incorporation of evaluation of $\mathrm{El}$ and its enhancement via counselling and workshops in medical curriculum to improve psychological health, academic performance, patient care and life satisfaction of future doctors.

\section{Limitations}

This study was questionnaire based crosssectional in design which may have caused bias due to self-reporting by students and represents observations only at a specific period in time. Moreover, before extrapolating the above findings to the general population, further statistical validations are required as our participants had almost similar sociodemographic characteristics.

\section{Conclusions}

In conclusion, our results indicate a high prevalence of psychological morbidity amongst newly admitted medical undergraduate students. The results also show that there was a significant negative correlation of psychological health scales with global trait EI scores as well as to all the four factors of trait 
El scores, further suggesting that people with higher El are more likely to have a better psychological health as compared to the people with lower El. Moreover, our study further shows that mental wellbeing and El are also affected by the environmental factors as depicted by the socio-demographic correlates.

\section{References}

Abdallah, A.R. \& Gabr, H.M. (2014) Depression, anxiety and stress among first year medical students in an Egyptian Public University, International Resarch Journal of Medicine and Medical Sciences, 2, 1, pp. 11-19 [online] Available at http://www.netjournals.org/ z_IRJMMS_14_005.html.

Abe, K., Evans, P., Austin, E.J., Suzuki, Y., Fujisaki, K., Niwa, M. \& Aomatsu, M. (2013) Expressing one's feeling and listening to others increase emotional intelligence: a pilot study of Asian Medical Students, BMC Medical Education, 13, 1, pp. 82.

Acharya, S. (2003) Factors affecting stress among Indian dental students, Journal of Dental Education, 67, 10, pp. 1140-1148 [online] Available at http://www.jdentaled.org/content/ 67/10/1140.long.

Arora, S., Ashrafian, H., Davis, R., Athanasiou, T., Darzi, A. \& Sevdalis, N. (2010) Emotional Intelligence in Medicine: A systemic review through the context of the ACGME competencies, Medical Education, 44, 8, pp. 749-764.

Arora, S., Russ, S., Petridez, K.V., Sirimanna, P., Aggarwal, R., Darzi, A. \& Sevdalis, N. (2011) Emotional intelligence and stress in medical students performing surgical tasks, Academic Medicine, 86, 10, pp. 1311-1317.

Austin, E.J., Saklofske, D.H. \& Egan, V. (2005) Personality, well being and health correlates of trait emotional intelligence, Personality and Indivisual Differences, 38, 3, pp. 547-558 [online] Available at: https://www.research gate.net/publication/222698367_Personality_w ellbeing_and_health_correlates_of_trait_emotio nal_intelligence.

Bayaram, N. \& Bilgel, N. (2008) The prevalence and socio-demographic correlations of depression, anxiety and stress among a group of university students, Social Psychiatry and Psychiatric Epidemiology, 43, 8, pp. 667-672.

Brannick, M.T., Wahi, M.M., Acre, M., Johnson, H.A., Nazian, S. \& Goldin, S.B. (2009) Comparison of trait and ability measures of emotional intelligence in medical students, Medical Education, 43, 11, pp. 1062-1068.
Chou, L.P., Li, C.Y. \& Hu, S.C. (2014) Job stress and burnout in hospital employees: comparisons of different medical professions in a regional hospital in Taiwan, British Medical Journal Open, 4, 2 [online] Available at: http://dx.doi.org/10.1136/bmjopen-2013004185.

Cooper, A. \& Petrides, K.V. (2010) A psychometric analysis of the Trait Emotional Intelligence Questionnaire-Short Form (TEIQue-sf) using item response theory, Journal of Personality Assessment, 92, 5, pp. 449-457.

Cooper, R.K. \& Sawaf, A.C. (1997) Executive EQ: Emotional intelligence in leadership and organization, New York: Grosset/Putnam.

Cozens, J. \& Greenhalgh, J. (1997) Doctors' perceptions of the links between stress and lowered clinical care, Social Science \& Medicine, 44, 7, pp. 1017-1022.

Dahlin, M., Joneborg, N. \& Runeson, B. (2005) Stress and depression among medical students a cross-sectional study, Medical Education, 39, 6, pp. 594-604.

Dahlin, M.E. \& Runeson, B. (2007) Burnout and psychiatric morbidity among medical students entering clinical training: a three year prospective questionnaire and interview-based study, BMC Medical Education, 7, 1 [online] Available at: http://bmcmededuc.biomed central.com/articles/10.1186/1472-6920-7-6.

Grant, K., Marsh, P., Syniar, G., Williams, M., Addlesperger, E., Kinzler, M.H. \& Cowman, S. (2002) Gender differences in rates of depression among undergraduates: measurement matters, Journal of Adolescence, 25, 6, pp. 613-617.

Harrod, N.R. \& Scheer, S.D. (2005) An exploration of adolescent emotional intelligence in relation to demographic characteristics, Adolescence, 40, 159, pp. 503.

Huppert, F.A. (2009) Psychological well-being: Evidence regarding its causes and consequences, Applied Psychology: Health and Well being, 1, 2, pp. 137-164.

lqbal, S., Gupta, S. \& Venkatarao, E. (2015) Stress, anxiety \& depression among medical undergraduate students \& their sociodemographic correlates, The Indian Journal of Medical Research, 141, 3, pp. 354.[online] Available at: http://www.ncbi.nlm.nih.gov/ pubmed/25963497.

Jafari, N., Loghmani, A. \& Montazeri, A. (2012) Mental health of Medical Students in Different Levels of Training, International Journal of Preventive Medicine, 3, 1, pp. 107-112 [online] Available at: https://www.ncbi.nlm.nih.gov/pmc/ articles/PMC3399312/. 
Lovibond, P.F. \& Lovibond, S.H. (1995). The structure of negative emotional states: Comparison of the Depression Anxiety Stress Scales (DASS) with the Beck Depression and Anxiety Inventories, Behaviour Research and Therapy, 33, 3, pp. 335-343.

Masood, A. \& Mazahir, S. (2015) Relational communication, emotional intelligence and marital satisfaction, International Journal of Research Studies in Psychology, 4, 4, pp. 3-11 [online] Available at: www.consortiacademia. org/index.php/ijrsp/article/download/1159/53

Mayer, J.D., Salovey, P. \& Caruso, D.R. (2008) Emotional Intelligence: New ability or Eclectic traits? American Psychologist, 63, 6, p. 503.

Melaku, L., Mossie, A. \& Nagesh, A. (2015) Stress among Medical Students and Its Association with Substance use and Academic performance, Journal of Biomedical Education, [online] Available at: http://dx.doi.org/ 10.1155/2015/149509

Nelis, D., Quoidbach, J., Mikolajczak, M. \& Hansenne, M. (2009) Increasing emotional intelligence: (How) is it possible? Personality and Individual Differences, 47, 1, pp. 36-41.

Nikolaou, I. \& Tsaousis, I. (2002) Emotional intelligence in work place: Exploring its effects on occupational stress and organizational commitment, The International Journal of Organizational Analysis, 10, 4, pp. 327-342. [online] Available at: https://www.research gate.net/publication/235253107_Emotional_Int elligence in the Workplace Exploring its Eff ects_on_Occupational_Stress_and_Organizati onal_Commitment.

Palmer, B., Donaldson, C. \& Strough, C. (2002) Emotional intelligence and life satisfaction, Personality and Individual Differences, 33, 7, pp. 1091-1100.

Petrides, K.V. \& Furnham, A. (2001) Trait emotional intelligence: Psychometric investigation with reference to established trait taxonomies, European Journal of Personality, 15, 6, pp. 425-448.

Petrides, K.V. \& Furnham, A. (2003) Trait emotional intelligence: behavioural validation in two studies of emotion recognition and reactivity to mood induction, European Journal of Personality, 17, 1, pp. 39-57 [online] Available at: https://www.researchgate.net/publication/ 227644180_Trait_Emotional_Intelligence_Beha vioural Validation in Two Studies of Emotio $n$ Recognition_and_Reactivity_to_Mood_Induc tion.
Petrides, K.V., Vernon, P.A., Schermer, J.A., Ligthart, L., Boomsma, D.I. \& Veselka, L. (2010) Relationship between trait emotional intelligence and the Big five in the Netherlands, Personality and Individual Differences, 48, 8, pp. 906-910.

Salovey, P. \& Mayer, J.D. (1990) Emotional Intelligence, Imagination, Cognition and Personality, 9, 3, pp. 185-211. [online] Available at: http://www.unh.edu/emotional intelligence/EIAssets/EmotionallntelligencePro per/El1990\%20Emotional\%20Intelligence.pdf

Sanchez-Ruiz, M.J., Perez-Gonzalez, J.C. \& Petrides, K.V. (2010) Trait emotional intelligence profiles of students from different university faculties, Australian Journal of Psychology, 62, 1, pp. 51-57.

Tavakol, M. \& Dennick, R. (2011) Making sense of Cronbach's alpha, International Journal of Medical Education, 2, pp. 53-55.

Weng, H.C., Hung, C.M., Liu, Y.T., Cheng, Y.J., Yen, C.Y. \& Chang, C.C. (2011) Associations between emotional intelligence and doctor burnout, job satisfaction and patient satisfaction, Medical Education, 45, 8, pp. 835842 [online] Available at: https://www.research gate.net/publication/51488452 Associations $b$ etween_emotional_intelligence_and_doctor_bu rnout_job_satisfaction_and_patient_satisfaction

Yelkikalan, N., Hacioglu, G., Kiray, A., Ezilmez, B., Soylemezoglu, E., Cetin, H., Sonmez, R. \& Ozturk, S. (2012) Emotional intelligence characteristics of students studying at various faculties and colleges of Universities, European Scientific Journal, 8, 8, pp. 33-50.

Yusoff, M.S.B., Abdul Rahim, A.F., Baba, A.A., Ismail, S.B., Mat Pa, M.N. \& Esa, A.R. (2013) The impact of medical education on psychological health of students: A cohort study, Psychology, Health \& Medicine, 18, 4, pp. 420-430, Available at: https://www. researchgate.net/publication/233389626_The_ $i$ mpact_of_medical_education_on_psychologica I_health_of_students_A_cohort_study. 